\title{
Mechanical Reliability Analysis of Pneumatic Solenoid Valve Considering Airflow Disorder
}

\author{
C. Y. Huang ${ }^{1}$, H. M. Su${ }^{1}$, B. S. Jian², C. L. Yao², and T. Y. Kam ${ }^{1 *}$ \\ ${ }^{1}$ Mechanical Engineering Department, National Chiao Tung University, Hsin Chu, Taiwan \\ ${ }^{2}$ Precision Forming System Technology Section, Metal Industries R\&D Centre, Kaohsiung, Taiwan \\ ${ }^{*}$ Corresponding author
}

Keywords: Solenoid valve, Reliability, Failure analysis.

\begin{abstract}
The mechanical reliability of a pneumatic solenoid valve is studied with the consideration of the failure mode of airflow disorder. The key mechanical components that have important effects on the improper airflow phenomenon are identified as the conical compression spring and rubber O-ring seal. The limit states of key components are constructed via the failure analyses of the components. The probability distributions of the random variables together with the limit states are used to determine the failure probabilities of the key components. A method established on the basis of the series system model is used to estimate the failure probability of the solenoid air valve for the failure mode of airflow disorder.
\end{abstract}

\section{Introduction}

Pneumatic solenoid valves have been broadly used in vehicles to perform automatic control task. Therefore, for safety reason, pneumatic solenoid valves have to be highly reliable and must have long fatigue lives. Recently, many research works have been focused on different aspects such as design, testing, applications, etc. of solenoid valves [1-4]. A typical two-port solenoid valve is shown in Fig. 1 .

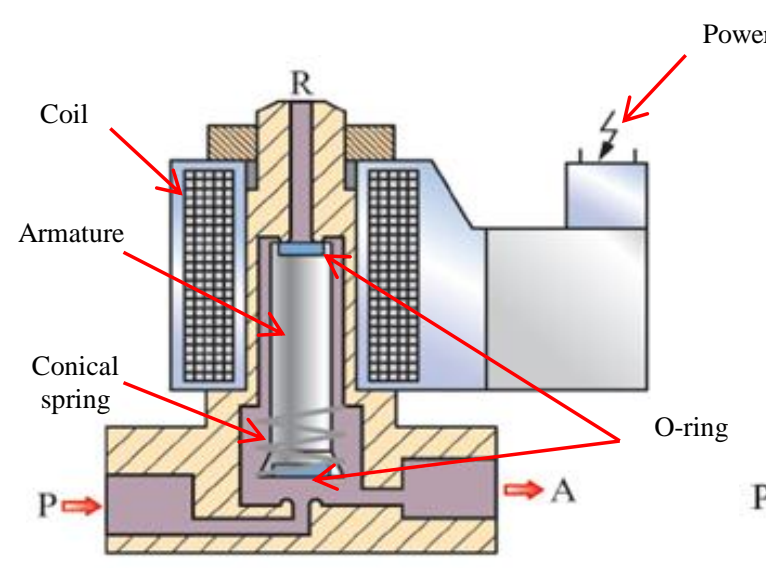

(a) Open condition

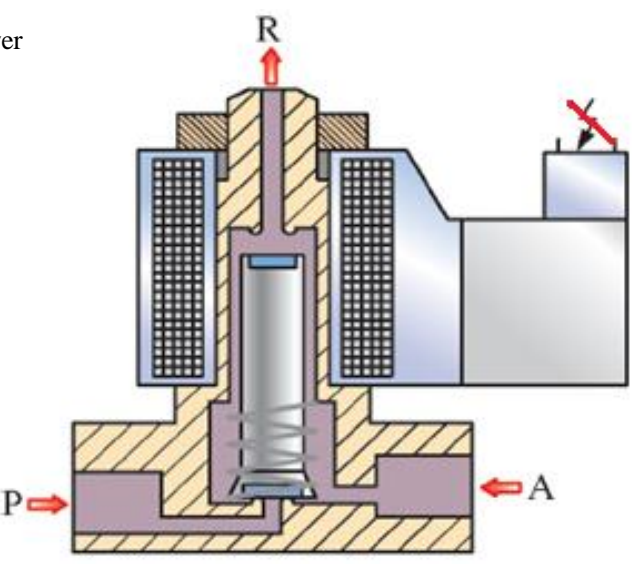

(b) Close condition

Fig. 1 Pneumatic solenoid valve

Regarding the function requirements of the solenoid valve, it may have different types of failure modes. The failure modes and the components/factors that cause these failure modes to occur are shown in Fig. 2. The solenoid valve is electromechanically actuated by the magnetic force generated by the electric current flowing in a solenoid. The conical compression coil spring together with the O-ring seal at the armature of the solenoid is used to regulate the air flowing from the orifice of the inlet port to the outlet port. The inlet port is closed when the conical spring is preloaded in 
compression to keep the O-ring seal in contact with the orifice of the inlet port. On the other hand, the inlet port is open when the solenoid exerts an additional compressive force to the spring to pull the O-ring seal away from the orifice of the inlet port. The solenoid valve is termed to be in normal condition when both closing and opening of the inlet port are perfect and controllable. The valve fails when either closing or opening of the input port becomes imperfect and uncontrollable.

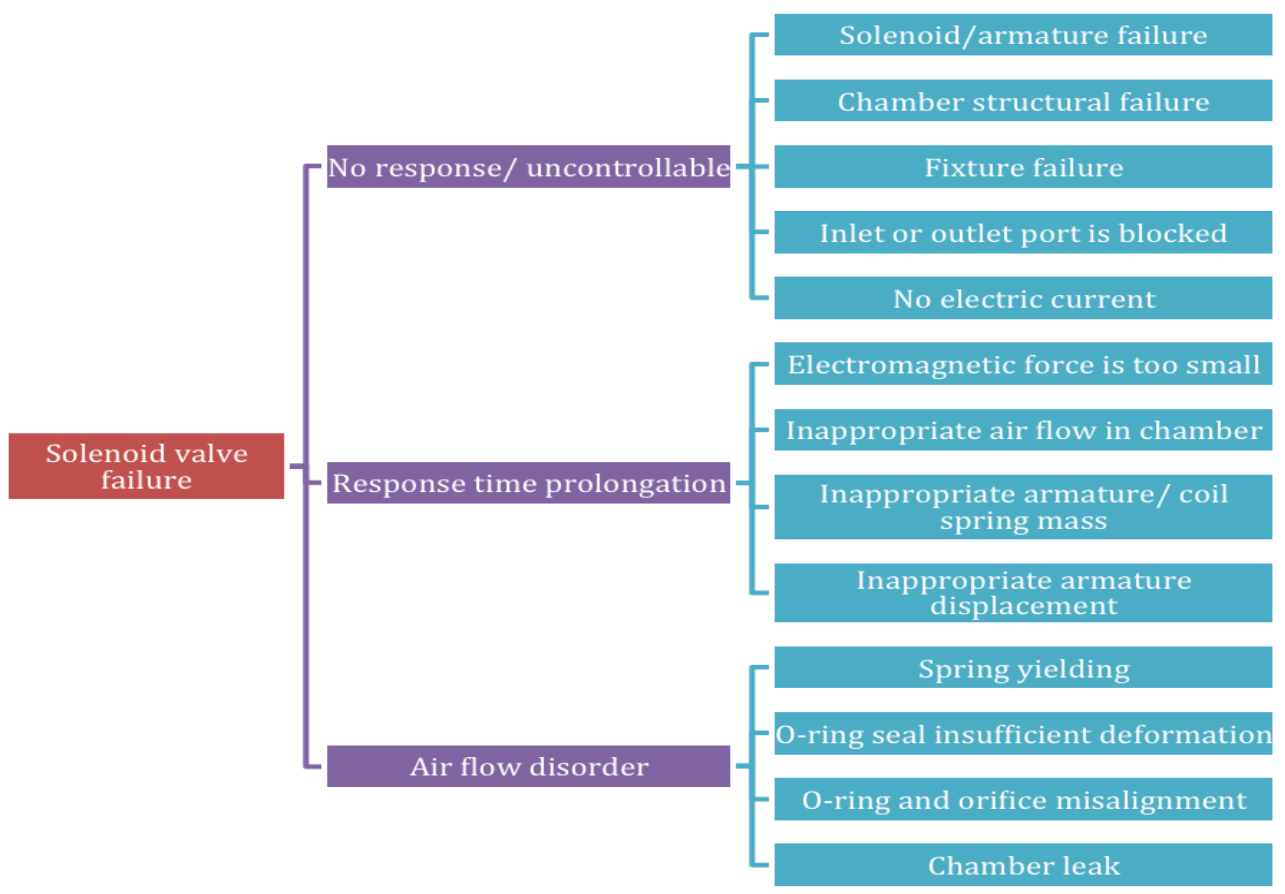

Fig. 2 Failure mode analysis of solenoid valve

In this study, the spring and O-ring seal are treated as the key components of which the failures can lead to the airflow disorder of the solenoid valve. Based on the adopted limit states, the failure probabilities of the spring and O-ring seal will be used to estimate the failure probability of the solenoid valve with respect to the failure mode of airflow disorder.

\section{Mechanical Analysis of Key Component}

The statistics of the mechanical and dimensional properties of the key components, for example those listed in Table 1 for the spring in Fig. 3, were measured experimentally.

Table1 Statistics of spring parameter

\begin{tabular}{|c|c|c|c|c|c|c|c|}
\hline Specimen Na & $\begin{array}{c}\text { Mass } \\
(\mathrm{g})\end{array}$ & $\begin{array}{c}\text { Wire } \\
\text { diameter } \mathrm{m} \\
(\mathrm{mm})\end{array}$ & $\begin{array}{c}\text { Large circle inner } \\
\text { diameter } \mathrm{D}_{\max } \\
(\mathrm{mm})\end{array}$ & $\begin{array}{c}\text { Small } \\
\text { circle } \\
\text { inner } \\
\text { diameter } \\
\mathrm{D}_{\min } \\
(\mathrm{mm})\end{array}$ & $\begin{array}{c}\text { Height } \mathrm{h} \\
(\mathrm{mm})\end{array}$ & $\begin{array}{c}\text { Closing } \\
\text { force } \\
(\mathrm{N})\end{array}$ & $\begin{array}{c}\text { Opening } \\
\text { force } \\
(\mathrm{N})\end{array}$ \\
\hline 1 & 1.02 & 0.95 & 10.12 & 6.40 & 13.830 & 9.898 & 11.858 \\
\hline 2 & 1.03 & 0.95 & 10.12 & 6.37 & 14.115 & 10.682 & 12.740 \\
\hline 3 & 1.03 & 0.95 & 10.15 & 6.49 & 14.355 & 10.976 & 13.132 \\
\hline 4 & 1.01 & 0.95 & 10.14 & 6.48 & 13.930 & 11.466 & 13.720 \\
\hline Mean & 1.023 & 0.95 & 10.133 & 6.435 & 14.058 & 10.756 & 12.863 \\
\hline $\begin{array}{c}\text { Coefficient of } \\
\text { variation }\end{array}$ & $6.875 \times 10^{5}$ & 0 & $1.688 \times 10^{4}$ & 0.003 & 0.040 & 0.324 & 0.458 \\
\hline
\end{tabular}


The equations for determining the deformation and maximum stress of the spring subjected to axial load $F$ are given, respectively, as

$$
\delta_{s}=F / k_{o} \quad \text { and } \quad \tau=k_{\mathrm{S} \min } 8 F \mathrm{D}_{\max } / \pi \mathrm{d}^{3}
$$

where $k_{o}$ is spring constant, $\delta_{s}$ shortening, $\tau$ shear stress, $k_{\mathrm{S} \text { min }}$ stress factor, $\mathrm{D}_{\max }$ inner diameter of large circle, and d wire diameter. It is noted that $k_{\mathrm{S} \min }=1+0.5 / \mathrm{C}_{\min }$ where $\mathrm{C}_{\min }$ is the ratio of small circle radius to wire thickness. To verify the accuracy of the shear stress obtained in eqn (1), the finite element code ANSYS is used to analyze the shear stress in the spring. It has been shown that similar to eqn (1), the finite element method also predict the same maximum shear stress at the bottom large circle as shown in Fig. 4.

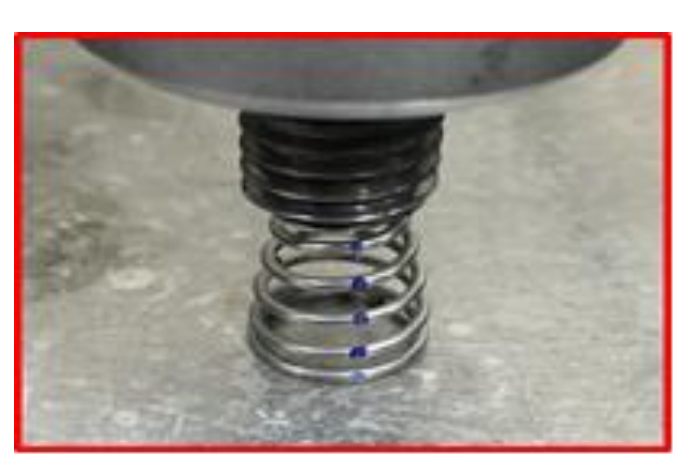

Fig. 3 Spring under static test

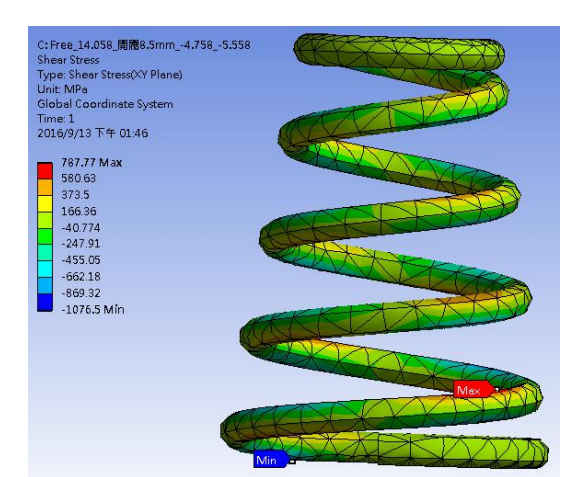

Fig. 4 Finite element analysis of spring (shear stress)

The differences between the stresses and displacements predicted by the two methods are less than $1 \%$. Therefore, the use of eqn (1) in the reliability analysis of the spring is feasible and acceptable. When the inlet port is closed, the O-ring seal (inner diameter $=2.6 \mathrm{~mm}$, outer diameter $=2.912 \mathrm{~mm}$ ) will be subjected to indentation force $P_{c}$. The deformation of the seal can be determined using the indentation relation between a rigid indenter and an elastic half space [5]

$$
\delta_{\mathrm{p}}=2 P_{c} \log \boldsymbol{a} /\left(\mathrm{E}_{\mathrm{p}} \pi^{2} \boldsymbol{a} \mathrm{A}_{\mathrm{p}}\right)
$$

where $\boldsymbol{a}$ is half width of the rigid indenter, $\mathrm{E}_{\mathrm{p}}$ Young's modulus, and $\mathrm{A}_{\mathrm{p}}$ contact area.

At the inlet port closing condition, the spring is pre-compressed to give a specific shortening $\delta_{0}$. Let $\mathrm{A}_{\mathrm{o}}$ be the orifice area and $p$ the air pressure of the inlet port. It is noted that the spring force $P_{o}$ should be equal to the sum of $p \mathrm{~A}_{\mathrm{o}}$ and $P_{c}$, ie, $P_{o}=P_{c}+p \mathrm{~A}_{\mathrm{o}}$. The indentation force then becomes $P_{c}=\left(\delta_{\mathrm{o}}-\delta_{\mathrm{p}}\right)$ $k_{o}-p \mathrm{~A}_{\mathrm{o}}$. The indentation should be greater than a prescribed value of $0.1 \mathrm{~mm}$. When the inlet port is in the opening condition, the solenoid exerts an additional compressive force, $P_{a}$, to the spring to pull the O-ring seal $\Delta_{\mathrm{a}}$ away from the orifice. At this time the total force acting on the spring is $F=\left(\Delta_{\mathrm{a}}+\delta_{\mathrm{o}}\right) k_{o}$.

\section{Mechanical Reliability of Solenoid Valve}

The airflow disorder of the solenoid valve caused by the size and material property variations or degradation of the key components is considered as one of the major failure modes of the valve. For the O-ring at closing condition, the limit state equation is written as

$$
\delta_{\mathrm{p}}-0.1 \mathrm{~mm}=\left(\delta_{\mathrm{o}} k_{o}-p \mathrm{~A}_{\mathrm{o}}\right) /\left[\left(\mathrm{E}_{\mathrm{p}} \pi^{2} \boldsymbol{a} \mathrm{A}_{\mathrm{p}} / 2 \log \boldsymbol{a}\right)+k_{o}\right]-0.1 \mathrm{~mm}=0
$$

For the spring at opening condition, the limit state equation is written as

$$
\tau-\tau_{\mathrm{a}}=k_{\mathrm{S} \min } 8\left(\Delta_{\mathrm{a}}+\delta_{\mathrm{o}}\right) k_{o} \mathrm{D}_{\max } / \pi \mathrm{d}^{3}-\tau_{\mathrm{a}}=0
$$

For this failure mode, the failure probability of the solenoid valve is

$$
\mathrm{P}_{\mathrm{f}}=\mathrm{P}\left[\left(\delta_{\mathrm{p}}-0.1<0\right) \mathrm{U}\left(\tau-\tau_{\mathrm{a}}>0\right)\right]
$$

where $\mathrm{P}[\bullet]$ denotes the probability of the event in the bracket. The reliability of the solenoid valve can also be defined as

$$
\mathrm{P}_{\mathrm{s}}=\mathrm{P}[\text { both spring and O-ring are reliable }]
$$

The solenoid valve used in severe environment may experience material degradation. Therefore, the material and size parameters $\mathrm{E}_{\mathrm{p}}, k_{o}, \delta_{\mathrm{o}}, \mathrm{D}_{\max }$, and $\mathrm{d}$ may vary during the lifetime of the solenoid valve. It is noted that in order to place the spring in the chamber, $\delta_{o}$ becomes a random variable and is related 
to the initial height of the spring. Herein, without loss of generality, all these parameters are treated as random variables with normal distributions. The means and standard deviations of $\delta_{\mathrm{p}}$ and $\tau$ can be derived from those of the parameters using the second moment method [6]. Let $\left[\mathrm{m}_{\delta \mathrm{p}}, \sigma_{\delta \mathrm{p}}\right]$ and $\left[\mathrm{m}_{\tau}, \sigma_{\tau}\right]$ be the [mean, standard deviation] of $\delta_{\mathrm{p}}$ and $\tau$, respectively. Then for instance, $\mathrm{m}_{\tau}$ and $\sigma_{\tau}$ can be obtained, respectively, as

and

$$
\mathrm{m}_{\tau}=k_{\mathrm{S} \min } 8 \mathrm{~m}_{F} \mathrm{~m}_{\text {Dmax }} / \pi \mathrm{m}_{\mathrm{d}}{ }^{3}
$$

$$
\sigma_{\tau}^{2}=\left(\partial \tau / \partial \mathrm{D}_{\max }\right)^{2} \operatorname{Var}\left[\mathrm{D}_{\max }\right]+(\partial \tau / \partial \mathrm{d})^{2} \operatorname{Var}[\mathrm{d}]+(\partial \tau / \partial F)^{2} \operatorname{Var}[F]
$$

where $\operatorname{Var}[\bullet]$ is variance of the random variable in the bracket. The standardized random variables of $\delta_{\mathrm{p}}$ and $\tau$ are written, respectively, as $\mathrm{U}_{\delta \mathrm{p}}=\left(\delta_{\mathrm{p}}-\mathrm{m}_{\delta \mathrm{p}}\right) / \sigma_{\delta \mathrm{p}}$ and $\mathrm{U}_{\delta \mathrm{p}}=\left(\tau-\mathrm{m}_{\tau}\right) / \sigma_{\tau}$. In view of eqn (6), the reliability $\mathrm{P}_{\mathrm{s}}$ of the solenoid valve is obtained as the product of the reliabilities of the key components, ie,

$$
\mathrm{P}_{\mathrm{s}}=\mathrm{P}_{\mathrm{s}, \mathrm{s}} \times \mathrm{P}_{\mathrm{s}, \mathrm{o}}
$$

with

$$
\mathrm{P}_{\mathrm{s}, \mathrm{s}}=\mathrm{F}_{\mathrm{U} \delta \mathrm{p}}\left[\left(\tau_{\mathrm{a}}-\mathrm{m}_{\tau}\right) / \sigma_{\tau}\right], \quad \mathrm{P}_{\mathrm{s}, \mathrm{o}}=1-\mathrm{F}_{\mathrm{U \delta p}}\left[\left(0.1-\mathrm{m}_{\delta \mathrm{p}}\right) / \sigma_{\delta \mathrm{p}}\right]
$$

For given $\mathrm{m}_{\delta \mathrm{p}}=0.2 \mathrm{~mm}, \sigma_{\delta \mathrm{p}}=0.05 \mathrm{~mm}, \tau_{\mathrm{a}}=680 \mathrm{MPa}, \mathrm{m}_{\tau}=430 \mathrm{MPa}$, and $\sigma_{\tau}=65.8 \mathrm{MPa}$, the failure probabilities of the spring and O-ring are 0.0001 and 0.0228 , respectively. The reliability $\mathrm{P}_{\mathrm{s}}$ of the pneumatic solenoid valve is then calculated as 0.9771 . It is noted that the quality of O-ring has great effects on the reliability of the solenoid valve. If the standard deviation $\sigma_{\delta p}$ is reduced to $0.02 \mathrm{~mm}$, the system reliability becomes 0.9999 which is a significant improvement to the reliability of the solenoid valve.

\section{Summary}

A method for evaluating the mechanical reliability of a pneumatic solenoid valve with the consideration of airflow disorder as the major failure mode has been presented. The key components related to this failure mode have been identified as the conical compressive spring and O-ring seal. The limit state equations of these components have been constructed to determine the failure probabilities of the components. The reliability of the solenoid valve has been estimated using the model of series system.

\section{Acknowledgement}

This research was financially supported by the Ministry of Economics (105-EC-17-D-11-1419), Taiwan.

\section{References}

[1] Y. Jiang, H. Y. Liu, Z. L., Xi, Chen, Research on intelligent test system for solenoid valve, J. Engineering \& Systems, 2 (2009) 25-31

[2] J. Chu, Y. Feng, Automatic control process of solenoid valve production line based on PLC and touch Screen, J. Smart Sensing \& Intelligent Systems, 6 (2013) 2217-2234.

[3] Y. Z. Jin, R. Y. Deng, Y. Z. Jin, X. D. Hu, Research on the response characteristics of solenoid valve of the air-jet loom by simulation, J. Thermal Science, 22 (2013) 606-612.

[4] L. C. Passarini, P. R. Nakajima, Development of a high-speed solenoid valve: An investigation of the importance of the armature mass on the dynamic response, J. Brazilian Society of Mechanical Sciences and Engineering, 25 (2003) 329-335.

[5] S. P. Timoshenko, J. N. Goodier, Theory of elasticity, McGraw-Hill Co., New York, 1970.

[6] J. R. Benjamin, C. A. Cornell, Probability, statistics, and decision for civil Engineers, McGraw-Hill Co., New York, 1970. 